\title{
Authoring Software in Special Education
}

\author{
Panayiota G. Smirni and Pearl Brereton \\ Department of Computer Science, Keele University \\ Keele, ST5 5BG, UK
}

\begin{abstract}
The limited quantity and quality of existing software (courseware) restricts the use of computers in today's special educational environments. Special educators are often reluctant to become involved with the development of new courseware because of the high costs associated with courseware development. Therefore in this paper we are focussing on procedures for the development of Computer-Assisted Instruction (CAI) lessons. Three primary techniques to help authors produce CAI lessons are the use of traditional programming languages, authoring languages, and authoring systems. These techniques are defined and compared. For our study we concentrated on those authoring systems which require no programming from the user and which provide a courseware generator for special teachers to enter their own content. These authoring systems can be divided into three categories according to the type of CAI lesson they support. Criteria are also given for selecting between the authoring systems.

An Authoring Courseware Development Model (ACDM) is proposed to guide the development of authored lessons. According to this model the development of special CAI lessons is separated into four phases: lesson design, lesson authoring, lesson testing and lesson documentation. It is hoped that by using this model from beginning to end, teachers will be rewarded for their time and effort with lesson products that can be used over time with students with learning difficulties.
\end{abstract}

\section{Introduction}

The diffusion of New Information Technology (NIT) in an ever increasing number of sectors of human activity within society, including education, special education, science and technology, as well as the workplace has shown the usefulness and effectiveness of NIT, and also its potential as an agent of change. In the educational environments this has yielded a vast amount of software packages aimed at supporting student's learning. As Flake, McClintock and Turner in [9] note, "The quantity of educational software, in particular, varies because most programmers who have produced educational software are without a conceptual background of instructional design".

The prospect of computer applications for children with learning difficulties is an exciting area, with great potential, but it is an area of research just beginning to be explored. There are many software packages available to the special teacher for teaching specific skills. Guidelines and sources of knowledge about selecting quality software are limited. Thus, many teachers experience frustration 
after purchasing poorly designed software packages which fail to help students achieve the desired learning outcome [21]. Some checklists use terms that are too technical for special teachers; some are disorganised and hard to follow; and some are too simplified to handle the wide array of software now on the market. None of the rating systems now available are systematic, comprehensive, and easyto-use by special teachers. More importantly, existing evaluation scales do not have adequate self-instructional training to aid the user becoming a proficient software critic [25].

As teachers gain aptitude with computers in special classrooms, many become interested in creating CAI lessons, referred to as 'courseware' to input their own content and modify program presentation features to meet local needs and seek advice about methods and media for use in such a project. Anyone who has ever developed a piece of CAI software knows that such an activity is a major undertaking, and decisions about which tools to use in the production of the program are crucial.

Software to help special teachers write their own instructional CAI program is available in the form of authoring software. There are a number of different types of authoring software however, and there is a great deal of confusion about the capabilities and purposes related to each of these. We have considered the advantages and disadvantages of each type and have examined factors such as ease of learning, ease and speed of use, power and efficiency, and support of various instructional strategies. Based on this analysis we advocate the use of those authoring systems which, basically, require no programming ability on the part of the user or author, and provide a lesson shell structure into which special teachers enter their own content. Additionally, technological and cognitive considerations are given for selection among different level of authoring systems.

Having selected an authoring tool special teachers have to face the process of developing CAI lessons. This process consists of four separate but related phases: 1) the design and creation of the instructional text (lesson design); 2) the development of the computer code so that the text might be offered via microcomputer (lesson authoring); 3) the testing of the designed lesson; and 4) the courseware documentation. A planning model that can guide the development of both CAI lesson design and lesson authoring is given. By using a systematic design approach from beginning to end, special teachers will be rewarded for their time and effort with lesson products that can be used over time with multiple learners.

\section{Computer-Assisted Instruction in Special Education}

There are many different and varied reasons why CAI has been used for students with special needs. Hogg in [16], listed the following features which are associated with students with learning difficulties (LD): a) difficulty making and extending associations; b) restricted ability to interpret abstractions; c) lack of intellectual curiosity; d) inability to generalise from observations; e) short attention span; and f) impoverished sensory perceptions. 
According to Conners et al in [5] CAI is used because it can provide: 1) individualisation; 2) motivation; and 3) active learning. There are also indirect advantages to using computers. For example generating programs for computers provides an opportunity to examine teaching materials in depth [10].

There are conflicting views concerning the effectiveness of CAI in Education. Several authors have commented that CAI is most effective when it is used to supplement traditional teaching methods rather than when it is used to replace it [23], [5]. According to Rude-Parkins (1983) the studies evaluating CAI are not unanimously favourable. Edwards et al in [6] say that in a review of the literature $45 \%$ of research studies are in favour of CAI, $40 \%$ find no difference between traditional and CAI methods of teaching and $5 \%$ produced mixed results.

The available software is generally of disappointing quality and the use of research-based components of instructional design and of the capabilities of microcomputers for colour, sound, and graphics is frequently lacking. The features of sound and colour may also be used inappropriately as Goldman and Pellegrino in [13] explain: 'Software packages that feature bells and whistles when students give wrong answers create at least two negative conditions: 1) they draw attention to the students and the activity becomes a punishing rather than a non-punishing environment; 2) students may prefer the consequences for incorrect responding more than those for correct. The software ends up motivating the student to respond incorrectly rather than correctly'. Often the software is not age appropriate and according to Ridge in [22] the age group of 16 years and over is being neglected. He advocated that the software used by young adults should be specifically designed for them.

Now that there is a wide range of software available to teachers of students with learning difficulties, it would be helpful if they had some criteria for determining in advance which CAI systems would be most effective for teaching specific knowledge, skills and concepts to particular individual student. Although the teacher may have some choice in selecting hardware and software for particular teaching purposes, at present there is little available research which would help with the selection of CAI systems to suit particular children.

\section{Authoring techniques for writing CAI lessons}

There are three categories of techniques used to help produce CAI lessons. These are: (a) traditional programming languages; (b) authoring languages; and (c) authoring systems.

The term traditional programming languages refers to the development of courseware through the use of programming languages, such as Basic, Fortran, $\mathrm{C}$, Pascal and so on.

The term authoring languages refers to a high-level computer language (similar in nature to the language of traditional programming) that enables the easy construction of courseware for use in an instructional environment [2]. An authoring language is enriched with simple commands supporting procedures typically needed for courseware development, such as presenting text, judging 
the accuracy of students' responses, presenting feedback, and maintaining students' records and a list of multiple-choice and 'essay' questions. The developer using an authoring language must construct the courseware by writing computer code. Sophisticated authoring languages like IPS, PILOT, MICROTEXT, COURSEWARE, TUTOR and STAF are commonly used over the past years.

The term authoring systems refers to a development environment which is much more restricted than the systems described above. It is a program or a set of programs which allow an instructor or instructional developer (teacher) to create courseware without programming. The teacher specifies the content to be taught and usually the instructional logic or strategy to be used. The authoring system automatically generates the debugged code which corresponds to these specifications[17].

In general, authoring systems are easier to use than authoring languages and, in turn, authoring languages are easier to use than traditional programming languages. However, traditional programming languages are usually more powerful and more efficient in their use of the microcomputer's capabilities than the authoring languages. Authoring languages, in turn, are usually more efficient and powerful than authoring systems.

The importance of these differences depends on the circumstances surrounding the development of CAI lessons. If limited time is available for CAI lesson development or the developers are naive in regard to computer programming, then he/she has to know that the more powerful the software, the more difficult and time consuming it will be.

Although very powerful, traditional programming languages such as Basic, or Fortran are so difficult that most teachers do not use them, unless they simply enjoy programming. Authoring languages will suit more teachers than will traditional programming languages, since they retain a good deal of power and flexibility while simplifying the programming task. However, teachers who choose an authoring language will still need programming aptitude and expertise, and will still find lesson development to be quite complex and time-consuming.

Authoring systems is a third choice. Such systems provide prompts for the teacher, usually making use of menus. The teacher fills in the content to be presented in response to the software prompts. Authoring systems are much easier and faster to use than are traditional programming languages or authoring languages. Their disadvantage is in their comparative lack of power and flexibility. Many educational decisions are made by the developer of the authoring system, and these decisions may not be to the liking of the teacher. Although this is a serious problem, authoring systems are the developing option that is best for the largest number of teachers.

Although there are considerable differences among authoring systems in terms of what they are capable of doing, they can be grouped into three primary categories [15]: 1) First-level authoring systems, which support the development of CAI lessons that are primarily drill and practice; 2) Second-level authoring systems, which support the development of CAI lessons that are more tutorial in nature; and 3) Third-level authoring systems, which support the development 
of CAI lessons based on a cognitive orientation to instruction, allowing learners to have a more active role in sequencing instructional content and selecting from a variety on instructional displays [20].

\section{Selecting an Authoring system}

Much current work focusses on the development of more sophisticated authoring systems [7]. Some authoring systems, such as HyperCard [11], are being enhanced and becoming more powerful, so that most instructional features can be included in CAI lessons. These authoring systems are capable of supporting a wide variety of instructional displays and place fewer restrictions on the instructional logic[19]. These authoring systems take advantage of more hardware options including synthesised speech, higher resolution graphics, and touch screens. Some of them provide a lesson shell structure (courseware generator) into which special teachers enter their own content. In this paper we will only be considering authoring systems that offer this facility.

Authoring system selection is an evaluation process involving description and judgement. Selection should be undertaken on the basis of local needs and, generally authoring systems will be needed if a substantial amount of courseware development is to be done by persons lacking programming skills, time, or interest. However, the identification of local needs should be more specific, since the focus of the selection effort will be to find one or more systems that match them [18].

There are several problems peculiar to authoring system evaluation. When researchers began investigating the technology in 1984, they were aware of half a dozen systems. A few years later, over sixty have been identified and undoubtedly more will appear. Their quicksilver nature makes selection especially difficult, since new systems often have innovative features and existing ones change constantly. In addition, selection is complicated because systems must be judged by their capabilities as authoring tools and by the products they produce. As more intelligent programs or those based on new learning theories appear, another generation of authoring tools will emerge [1]. While both such systems might not exactly fit existing criteria, most can be presumed to apply. In fact the criteria are probably more stable than the technology.

\subsection{Selection criteria}

There are technological and cognitive considerations in the selection of the authoring systems proposed. These considerations fall into the following categories:

1. authoring environment (hardware requirements, training requirements, and ease of use);

2. lesson content creation (text, graphic, and sound);

3. lesson definition (structure of lessons, display strategies, student response processing, and branching sequences); and 
4. course management (student management, scoring data, summary information or student performance).

The criteria given above are not exhaustive and are not all likely to be universally applicable but they hopefully illustrate the range of factors that need to be considered when investigating authoring systems. Any reasonably objective assessment will involve setting up a rating sheet so that each authoring system under consideration can be evaluated against established criteria. It may then be necessary to assess the different criteria to reflect the relative importance of each.

To illustrate the point a subset of the above criteria is used to examine some of the features in which two authoring systems, ToolBook and HyperCard 2.0 differ.

- Graphics: The most common types of graphic images are bitmapped (paint) graphics and object-oriented (draw) graphics. Using HyperCard, developers can create and edit bitmapped graphics using the paint tools provided, but there is no provision for creating or manipulating object-oriented graphics. In ToolBook, as there are no paint tools, bitmapped graphics must be created in other paint programs and imported into ToolBook. However, ToolBook does support the creation and editing of draw objects. It is generally desirable to use draw graphics rather than paint graphics, since it uses less space.

- User Interface: In HyperCard there are five levels of interaction (browsing, typing, authoring, painting and scripting). In ToolBook there are two (reader and author) which makes it easier for the user.

- Printing: HyperCard's printing capabilites are much more powerful than those in ToolBook.

- Other differences:

- In ToolBook commands to control keyboard input are available. In HyperCard external commands have to be used to obtain the same results.

- In ToolBook, all objects can be in colour, including fields and buttons. HyperCard 2.0 only supports colour graphics displayed in additional viewing windows which are manipulated by external programming commands.

- Additional memory is also required to display HyperCard's colour graphics.

\section{Development of CAI Lesson}

To produce quality CAI lessons, competence is needed in the subject matter, skill with an authoring program, and knowledge of systematic instructional design [24]. While most guidelines espouse a systematic approach to courseware design, the successful designer often depends as much on personal experience and intuition as she/he does on any systematic approach. This occurs because: a) we do not have a clear concept of the uniqueness of the computer-assisted learning 
experience or of the computer as a medium; b) instructional systems design principles do not map easily or directly into CAI; c) learning theories and research do not always produce obvious principles for practice. Most novice authors of courseware understand neither the planning time nor the process required for creating CAI materials. Because the tools offered by authoring programs have specified the process of development, the complexity of design can easily be overlooked [14]. Estimates for developing interactive CAI materials range from 15 to 400 hours, depending on their type and complexity [3]. Experienced developers suggest that between $60 \%$ and $80 \%$ of courseware development is taken up in planning time [24].

A variety of formal instructional design and development (IDD) models exist that are based on the systems approach suggested by Gagne and Briggs in [12]. An effective approach for the special teacher is to adapt an IDD model and systematically implement the steps of pre-planning, designing, authoring, testing and revising as the courseware product is developed. The Courseware Authoring Process (CAP) model illustrates this sequence [8]. In this paper an alternative approach to creating effective CAI courseware for special students is proposed.

\subsection{Authoring Courseware Development Model}

The research on CAI has demonstrated that the use of microcomputers does not necessarily enhance the quality of the instructional text [4]. Therefore it is important to consider what factors might enhance CAI lessons. Although these factors are involved in the design of CAI lessons, they have implications for authoring.

Based on the characteristics which are bound to the CAP, the proposed Authoring Courseware Development Model (ACDM) (see Fig. 1.) consists of four separate but related phases:

1. the design and creation of the instructional text;

2. the development of the computer code so that the text might be offered via microcomputer; and

3. the testing of the designed lesson and

4. the courseware documentation.

The first phase is called "lesson design"; the second phase is called "lesson authoring"; the third phase is called "lesson testing"; and the last phase is called "lesson documentation". When carefully and appropriately designed instructional text is turned into CAI lessons the results are usually encouraging. It seems a truism that the quality of the final CAI lesson is more a function of lesson design than lesson authoring or lesson testing or lesson documentation.

In the "lesson design" phase the teacher has to provide the exact plan for how the lesson will operate by giving the: a)definition of target population; b) goals for the program; c)organisation and orientation of content toward objectives; $d$ ) definition of prerequisite skills; e) appropriateness of the content for intended users; f) presentation of the content; g) effectiveness and appropriateness of the 
$\underline{A} \underline{C} \underline{\underline{M}}$

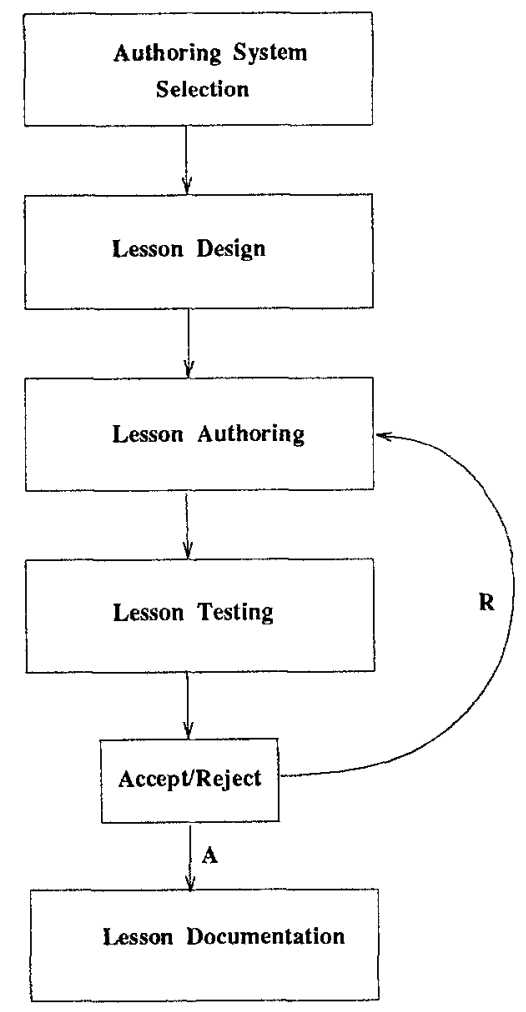

Fig. 1. Authoring Courseware Development Model

feedback (confirmational, motivational, instructional); and h) learners interaction with the program.

In the "lesson authoring" phase the teacher has to: a) select an authoring system and learn the mechanics of using an authoring system; b) learn the use of the courseware generator (editing existing activities and writing new activities) as part of the database courseware program; and c) begin creating the lesson (assessment activities).

In the "lesson testing" phase the teacher has to prepare a pilot test (a peer review process followed by a pilot-tested with students) to find out whether or not the lesson works as intended.

If the lesson does not work smoothly the teacher has to search for another authoring system and she/he has to restart from the "lesson authoring" phase, otherwise she/he can proceed to the next phase, -the "lesson documentation" phase-, where the courseware should be considered complete and she/he has to write a courseware documentation including: a) description of the objectives and 
content; b) users groups; c)prerequisite skills; d) implementation guidelines; and d) supportive materials.

After all the phases are completed the system is ready for use.

\section{Conclusions}

Powerful authoring systems, which provide customised courseware generators, offer special educators the means to create CAI lessons to fit student needs. Developing a courseware requires curriculum expertise, skills with an authoring system and knowledge of CAI design. Using the Authoring Courseware Development Model (ACDM) to guide the development process we hope to improve the efficiency and quality of the final product and increase significantly the costeffectiveness of courseware development.

\section{References}

1. Allen, M.A.: A new approach to authoring CBE courseware. Paper presented at the Sixth Interservice/Industry Training Equipment Conference Washington D.C. (1984)

2. Barker, P.G., Singh, R.: Authoring languages for computer-based learning. British Journal of Educational Technology 13(3) (1982) 167-196.

3. Barron, A.: Instructional design for computer-based instruction. Paper presented at a faculty workshop West Virginia University Morgantown (1990)

4. Clark, M.M.: Educational Technology and children with moderate learning difficulties. Exceptional Child 33(10) (1986) 28-34

5. Conners, F.A., Caruso, D.R., Detterman, D.K.: Computer-assisted instruction for the mentally retarded. In: N.R. Ellis, N.W. Bray (eds.): International Review of research in mental retardation. Academic Press Inc New York XIV (1986) 105-134

6. Edwards, J., Norton, S., Taylor, S., Weiss, M., Dusseldorp, R.: How effective is CAI? A review of the research. Educational Leadership 22 (1975) 25-34.

7. Fairweather, P.G., O'Neal, A.F.: The impact of advanced authoring systems on CAI productivity. Journal of Computer-Based Instruction 11(3) (1984) 90-94.

8. Fitzerald, G.: Authoring systems for higher education. Postdoctoral training session presented at CEC Project Retool. New York: Long Island University (1989)

9. Flake, J.L., McClintock, C.E., Turner, S.V.: Fundamentals of Computer Education. Belmont, CA: Wadworth Publishing (1985)

10. Fleischner, K., Nuzum, M.B., Marzola, E.S.: Devising an instructional program to teach arithmetic problem-solving skills to students with learning disabilities. Journal of Learning Disabilities 20(4) (1987) 214-217

11. Friedler, Y., Shabo, A.: Using the HyperCard Program to Develop a customised courseware generator for school use. Educational Technology (1989) 47-51

12. Gagne, R.M., Briggs, L.J.: Principles of instructional design. New York: Holt, Rinehart, and Winston (1979)

13. Goldman, S.R., Pellegrino, J.L.: Microcomputer: Effective Drill and Practice. Academic Therapy 22(2) (1986) 133-140

14. Hannafin, K., Mitzel, H.: CBI authoring tools in postsecondary institutions: A review and critical examination. Computers and Education 14(3) (1990) 197-204 
15. Hannum, W.H.: Techniques for creating Computer-Based Instructional Text: Programming Languages, Authoring Languages, and Authoring Systems. Educational Psychologist 21(4) (1986) 293-314

16. Hogg, B.: Microcomputers in special needs: A guide to good practice. National Council for Special Education 1 Wood Str. Stafford Upon Avon CV37 6JE (1984)

17. Kearsley, G.P.: Authoring systems in computer-based education. Communications of ACM 25(7) (1982) 429-437

18. Locatis, C.N., Carr, V.H.: Selecting authoring systems. Journal of Computer-Based Instruction 12(2) (1985) 28-33

19. Locatis, C.N., Carr, V.H.: Authoring systems and assumptions about them. Journal of Biomedical Communication 13(2) (1986) 4-9

20. Merrill, M.D., Wood, L.: Computer guided instructional design. Journal of Computer-Based Instruction 11(2) (1984) 60-63

21. Preece, J.: Selecting CAL Packages: Helping teachers to recognise quality software. Computer Technology (1984) 20-21

22. Ridge, V.: Computers in Special Education. Teaching and Training 24(2/3) (1986) 216-230

23. Rude-Parkins, C.: Microcomputer and learning disabled adolescents. The Pointer 27(4) (1983) 14-19

24. Sampath, S., Quaine, A.: Effective interface tools for CAI authors. Journal of Computer-Based Instruction 17(1) (1990) 31-34

25. Wright, E.B., Forcier, R.C.: The Computer: A Tool for the Teacher. Belmont, CA: Wadworth Publishing (1985) 